\title{
MACROD2 Polymorphisms Are Associated with Hypertension in Korean Population
}

\author{
Bokyung Ko, Hyun-Seok Jin
}

Department of Biomedical Laboratory Science, College of Life and Health Sciences, Hoseo University, Asan, Korea

\section{한국인에서의 MACROD2 유전자 다형성과 고혈압 상관성 연구}

\author{
고보경, 진현석 \\ 호서대학교 생명보건대학 임상병리학과
}

\begin{abstract}
Hypertension is caused by a combination of genetic and environmental factors. In advanced countries, more than $30 \%$ of adults have hypertension. Among the genetic factors affecting hypertension, there are reports from European cohort studies that variants of the MACROD2 gene are correlated with blood pressure and the hypertension status. In this study, genetic polymorphisms of the MACROD2 gene region were selected and extracted based on Korean Genome and Epidemiology data, and logistic regression analysis was then performed for the hypertensive state. Linear regression analysis was also performed for the systolic and diastolic blood pressure. As a result, 16 SNPs showed a statistically significant association with a hypertensive state, and 2 SNPs (rs16996211, rs6034240) showed statistical significance, even in blood pressure. The most significant rs16996211 had a relative risk of hypertension of 0.85 (Cl: $0.76 \sim 0.95, P=3.1 \times 10^{-3}$ ), as well as an association with the systolic blood pressure (beta $=-0.75$, $P=0.024$ ) and diastolic blood pressure (beta $=-0.59, P=0.01$ ). These results suggest that polymorphisms of the MACROD2 gene are associated with hypertension in both Caucasians and Koreans, and highlight the potential genetic correlations with the pathogenesis of hypertension.
\end{abstract}

Key words: Association, Blood pressure, Hypertension, MACROD2, SNP

This is an Open Access article distributed under the terms of the Creative Commons Attribution Non-Commercial License (http://creativecommons.org/licenses/by-nc/4.0) which permits unrestricted non-commercial use, distribution, and reproduction in any medium, provided the original work is properly cited.

Copyright $\odot 2019$ The Korean Society for Clinical Laboratory Science. All rights reserved.
Corresponding author: Hyun-Seok Jin Department of Biomedical Laboratory Science, College of Life and Health Sciences, Hoseo University, 20 Hoseo-ro 79 Beon-gil, Asan 31499, Korea

Tel: 82-41-540-9968

Fax: 82-41-540-9997

E-mail: jinhs@hoseo.edu

ORCID: https://orcid.org/0000-0002-3673-9806

Received: October 10, 2018

Revised $1^{\text {st: }}$ : November 23, 2018

Revised $2^{\text {nd. }}$ : January 8, 2019

Accepted: January 9, 2019

\section{서 론}

고혈압은 혈압이 정상 범위보다 높은 상태로 유지되는 만성 질환을 의미한다. 이완기 혈압이 $90 \mathrm{mmHg}$ 이상이거나수축기 혈압이 $140 \mathrm{mmHg}$ 이상일 때를 고혈압으로 정의하고 있다[1]. 고혈압은 뇌졸중이나 허혈성 심장병 등의 합병증을 유발하여 전 세계적으로 매년 1천만 명 이상의 사망자를 낸다[2, 3]. 반대 로 혈압을 낮추면 뇌졸중 발병이 현저하게 감소한다[4]. 고혈압 은 선진국에서 약 $30 \%$ 의 성인에게 영향을 미치는 만성 질환이 다. 고혈압의 원인으로는 유전적 인자와 환경적 위험요소의 상
호작용으로 인해 발생하는 복합 질환이기 때문에 고혈압의 병 인과 발생에 영향을 미치는 유전적 요인의 연구는 현재도 계속 진행 중이다[5]. 지난 20년간 우리나라 만성질환 중 유병률이 가장 높은 질환은 고혈압으로, 2018년 질병관리본부에서 발표 한 2016 국민건강통계 결과에 의하면 고혈압 유병률(만 30세 이상, 표준화)은 2010년 28.9\%에서 2016년에는 33.5\%로 노인 인구의 증가에 따라 점차 증가 추세이며, 만 30세 이상 성인 3명 중 1명(29\%, 2016년 국민건강영양조사 기준)은 고혈압을 않고 있는 것으로 나타났다[6].

현재까지 다양한 유전자들이 고혈압과 상관관계가 있는 것 
으로 알려져 있는데[7-9], 그 중에서 MACROD2 (MACRO domain containing 2) 유전자가 심혈관 질환 및 고혈압과 상관 관계가 있는 것으로 발표되었다[10-13]. MACROD2는 mono$\mathrm{ADP}-$ ribosylated 된 단백질로부터 ADP-ribose를 제거하는 데 관여하는 탈아세틸화효소의 기능을 가지고 있는데, DNA 손 상 시 핵에서 세포질로 전위하는 것으로 나타났으며, 이는 태아 와 성인의 뇌, 흥선, 골격근, 간, 췌장, 전립선, 신장, 폐에서 발현 하며 쥐 배아와 성체의 in situ hybridization과 RT-PCR분석에 서 배아일 12.5 일에서 성년기까지 두뇌, 특히 심실영역에서의 발현을 나타냈다[14]. 또한 MACROD2 exon 결실이 비만에 영 향을 미칠 수 있다는 연구 결과[15]를 바탕으로 본 연구에서는 한국인 유전체 역학 데이타를 기반으로 하여 MACROD2 유전 자의 다형성과 고혈압과의 상관 관계를 조사 분석하였다.

\section{재료 및 방법}

\section{1. 연구대상자}

본 연구를 위한 한국인 연구대상자는 한국인 유전체 역학 조 사 사업(Korean genome and epidemiology, KoGES)의 일환 인 Korean association resource (KARE)를 기반으로 하였다 [16]. 본 연구에 사용한 유전 정보와 역학 정보는 질병관리본부 인체자원은행에서 분양을 받아 사용하였다(2017-046). 이러 한 정보는 질병관리본부에서 경기도 안성 지역과 안산 지역 거 주자들을 대상으로 한국인 역학 및 유전체 연구를 위한 코호트 연구이다. 40 세에서 69 세 사이의 10,038 명을 모집하였으며, 이들 중에서 QC (Quality Control) 과정을 통해 분석 기준에 적 합하지 않은 1,196 명이 제외되어 8,842명(남성: 4,183명, 여 성: 4,659명)이 분석에 가능한 연구 대상자였다. 본 연구에서는 고혈압에 대한 유전 변이와의 상관성 연구가 목적이기 때문에 8,842 명의 대상자 중에서 고혈압 환자와 대조군을 선별하였는 데 유전형에 따른 수축기 혈압과 이완기 혈압에 대한 선형 회기 분석에서는 고혈압 약을 복용하거나 혈압에 영향을 줄 수 있는 약물을 복용하고 있는 1,291 명을 제외한 7,551명을 대상으로 하였다. 고혈압 환자군과 건강 대조군 사이의 유전형 빈도 차이 에 대한 로지스틱 회귀 분석을 위해서는 수축기 혈압이 140 $\mathrm{mmHg}$ 이상이거나 이완기 혈압이 $90 \mathrm{mmHg}$ 이상인 사람들과 여기에 고혈압 치료를 받고 있는 환자 961명을 고혈압 환자군 에 포함하여 총 1,968 명을 선정하였고, 건강 대조군 $(\mathrm{N}=4,452)$ 에는 수축기 혈압이 $120 \mathrm{mmHg}$ 미만이면서 동시에 이완기 혈 압이 $80 \mathrm{mmHg}$ 미만을 만족하는 사람으로 정의하였다. 고혈압 환자군과 건강 대조군의 평균 나이는 각각 $49.4 \pm 8.11$ 세와
$56.8 \pm 8.44$ 세로 통계적으로 유의하게 차이가 있었다. 본 연구 에 활용한 유전 정보는 질병관리본부 국립보건연구원 $(\mathrm{KNIH}$, National Institutes of Health)과 호서대학교에서 연구윤리 승 인을 받은 후 분석을 수행하였다(1041231-170822-BR062-01).

\section{2. 혈압 측정 방법}

혈압 측정은 숙련된 간호사가 대상자의 팔 둘레에 적절한 크 기의 커프를 사용하여 수은 혈압계(Baumanometer; W. A. Baum, Copiague, NY, USA)로 혈압을 측정하였다. 첫 번째 혈 압 측정 전에 연구대상자는 5 분 동안 휴식을 취하게 하였다. 그 리고 연구대상자는 누운 자세를 유지한 상태에서 5 분 간격 이상 의 시간차이를 두고 3 번 측정하여 평균값을 분석에 사용하였다.

\section{3. 유전형 분석과 Single Nucleotide Polymorphism (SNP) 선별}

본 연구에서는 $\mathrm{KARE}$ 유전형 자료를 기반으로 SNP (Single nucleotide polymorphism)을 선별하였다. DNA 시료는 연구 참여자의 말초혈액에서 분리 추출하였고, 유전형 판독을 위해 서는 Affymetrix genome-wide human SNP array 5.0 (Affymetrix Inc., Santa Clara, CA, USA)를 사용하였다. 유전 형 판독 정확도가 $98 \%$ 이하이거나, $4 \%$ 이상의 높은 missing genotype call rate을 보이거나, 30\% 초과의 heterozygosity 를 가지거나, 성별 불일치가 존재하는 대상자들은 제외되었다. 본 연구에서 분석한 $M A C R O D 2$ 유전자 영역은 전사체 $(2 \mathrm{Mb})$ 양말단에서 $5 \mathrm{~kb}$ 씩 확장하여 이 범위에 존재하는 341 개 $\mathrm{SNP}$ 들 을 선택하였다. 이 SNP들의 염색체 상의 위치는 UCSC (University of colombo school of computing) Genome browser on human Mar. 2006 (NCBI human genome build 36)를 기준으로 하였다.

\section{4. 상관성 분석과 통계 분석}

대부분의 통계 분석에는 PLINK version 1.07 (http://pngu.mgh.harvard.edu/ purcell/plink)과 PASW Statistics version 18.0 (SPSS Inc. Chicago, IL, USA)을 사용하 였다. 고혈압 환자군과 건강 대조군에 대한 유전적 변이의 상관 성 분석은 로지스틱 회귀 분석을 사용하였으며 additive genetic model을 기반으로 하였다. 그리고 수축기 혈압 및 이완 기 혈압과 유전적 변이의 상관분석은 선형 회귀분석을 사용하였 다. 그리고 이러한 회귀 분석의 시행에 있어서 나이, 지역, 성별을 공변수로 처리하여 분석하였다. 분석 값에 대한 유의수준은 0.05 
이하를 기준으로 하였다. Regional association plots을 확인하 기 위하여 웹 기반 프로그램인 Locuszoom version 1.1 (http://csg.sph.umich.edu/locuszoom)을 사용하였다[17].

\section{결 과}

\section{1. $M A C R O D 2$ 유전자와 고혈압과의 로지스틱 회귀 분석}

연구 대상자들의 임상 표현형 특징은 Table 1 에 정리하였다. 고혈압 환자(n=1,968)의 평균 나이, 평균수축기 혈압(Systolic blood pressure; SBP), 평균 이완기 혈압(Diastolic blood pressure; $\mathrm{DBP})$ 은 각각 $56.75 \pm 8.44$ 세, $139.42 \pm 17.27$ $\mathrm{mmHg}, 88.97 \pm 10.90 \mathrm{mmHg}$ 으로 나타났다(Table 1). 정상 혈압군과 고혈압 환자의 Student $t$-검정에서 $\mathrm{SBP}, \mathrm{DBP}$ 의 유의 한 통계적 차이가 있었는데, 예상하듯이 고혈압 환자군에서 모 두 높은 수치를 나타냈다(Table 1).

본 연구 대상인 $M A C R O D 2$ 는 매우 긴 전사체 $(2 \mathrm{Mb})$ 를 지닌 유전자로 분석 대상 SNP들은 NCBI human genome build 36 를 기준으로 하여 20 번 염색체에서 341 개의 SNP들이 분석 대 상에 해당하였다. 선별된 $M A C R O D 2$ 의 341 개 $\mathrm{SNP}$ 을 대상으 로 고혈압 환자군과 건강 대조군에 대한 로지스틱 회귀 분석에 는 연령, 성별 및 지역을 공변수로 처리하였다. 유전 모델은 additive genetic model을 기반으로 하였다. 그 결과 16개 SNP 에서 통계적으로 유의한 상관관계 $(P<0.05)$ 를 확인할 수 있었 다(Table 2). 이 중 가장 높은 유의 수준 $\left(P=3.1 \times 10^{-3}\right)$ 을 보여주 는 SNP은 rs16996211으로 상대적 위험도는 0.85 $95 \%$ 신뢰구 간: 0.76 0.95)인 것으로 나타났다(Figure 1). Minor allele인 $\mathrm{T}$ 염기의 빈도를 살펴보면 고혈압 환자군에서는 $16.1 \%$ 이고, 건
강 대조군에서는 $18.7 \%$ 로 약 $2.6 \%$ 의 빈도 차이가 있어서 $\mathrm{T}$ 염 기를 보유할 경우에 고혈압 상태에 대한 상대적 위험도가 낮아 지는 방향으로 유의한 상관 관계가 있는 것을 알 수 있었다. 또한 rs16996211은 수축기 혈압과 이완기 혈압에서도 통계적 유의 수준을 보여주고 있는데, minor allele를 보유할 수록 점진적으 로 혈압 수치가 낮아지는 경향을 보여주고 있다. 이러한 결과는 minor allele를 가질수록 고혈압에 대한 상대적 위험도가 낮아 지는 환자-대조군 분석 결과와 일치하고 있었다.

\section{2. $M A C R O D 2$ 유전자와 혈압과의 선형 회귀 분석}

341 개의 SNP들을 대상으로 수축기 혈압과 이완기 혈압에 대 해서도 상관 분석을 시행하였다. 선형 회귀 분석을 하였으며 역 시 연령, 성별 및 지역을 공변수로 처리하였다. 유전 모델은 additive genetic model을 기반으로 하였다. 그 결과 수축기 혈 압(SBP)에서는 17 개의 SNP들이, 이완기 혈압(DBP)에서는 23 개의 $\mathrm{SNP}$ 들이 각각 통계적으로 유의한 상관 관계를 보여주고 있었다.

수축기 혈압에서는 rs383329이 가장 높은 유의 수준을 나타 냈고 $\left(\beta=-1.928, P=1.3 \times 10^{-3}\right), \mathrm{DBP}$ 에서는 $\mathrm{r} 56135644$ 이 가장 높은 유의 수준을 나타냈다 $\left(\beta=-1.2, P=1.6 \times 10^{-3}\right)$. 그리고, 11 개의 $\mathrm{SNP}$ ( $\mathrm{rs} 7268327$, rs595247, rs424240, rs383329, rs367595, rs65567, rs17694839, rs6110694, rs16996211, rs6043560, rs6135644)들은 수축기 혈압(SBP)과 이완기 혈압 (DBP) 모두에서 통계적 유의성을 보여주고 있으며, 이들 SNP 들이 minor allele를 보유하고 있을 때 보여주는 혈압수치의 방 향성 또한 수축기 혈압과 이완기 혈압에서 모두에서 일치하고 있다.

Table 1. Basic characteristics of the subjects in the KARE

\begin{tabular}{|c|c|c|c|c|}
\hline \multirow{2}{*}{ Characteristics } & \multirow{2}{*}{ Quantitative trait analysis* } & \multicolumn{3}{|c|}{ Case-control analysis** } \\
\hline & & Normotensive & Hypertensive & $P$-value ${ }^{\star \star \star}$ \\
\hline Number of subjects & 7,551 & 4,452 & 1,968 & \\
\hline Gender [men (\%)/women (\%)] & 3,747 (49.6)/3,804 (50.4) & $2,061(46.3) / 2,389(53.7)$ & $910(46.2) / 1,058(53.8)$ & 0.955 \\
\hline Age ( $M$ years $\pm S D)$ & $51.44 \pm 8.78$ & $49.39 \pm 8.11$ & $56.75 \pm 8.45$ & $<0.0001$ \\
\hline $\begin{array}{l}\text { Systolic blood pressure (SBP) } \\
(\mathrm{M} \mathrm{mmHg} \pm \mathrm{SD})\end{array}$ & $115.65 \pm 17.25$ & $104.69 \pm 9.15$ & $139.42 \pm 17.27$ & $<0.0001$ \\
\hline $\begin{array}{l}\text { Diastolic blood pressure (DBP) } \\
\quad(\mathrm{M} \mathrm{mmHg} \pm \mathrm{SD})\end{array}$ & $74.21 \pm 11.27$ & $67.68 \pm 7.72$ & $88.97 \pm 10.90$ & $<0.0001$ \\
\hline Total cholesterol $(\mathrm{M} \mathrm{mg} / \mathrm{dL} \pm \mathrm{SD})$ & $190.68 \pm 35.71$ & $188.05 \pm 34.16$ & $197.37 \pm 37.70$ & $<0.0001$ \\
\hline $\begin{array}{l}\text { High density lipoprotein cholesterol } \\
(\mathrm{M} \mathrm{mg} / \mathrm{dL} \pm \mathrm{SD})\end{array}$ & $44.85 \pm 10.03$ & $45.05 \pm 9.92$ & $43.73 \pm 10.26$ & $<0.0001$ \\
\hline Triglyceride ( $\mathrm{M}$ mg/dL $\pm S D)$ & $159.97 \pm 105.54$ & $146.90 \pm 95.75$ & $190.22 \pm 115.38$ & $<0.0001$ \\
\hline
\end{tabular}

Abbreviations: KARE, Korean association resource; $\mathrm{M}$, mean value; SD, standard deviation. *Individuals who are not using hypertensive medications. ${ }^{* *}$ Controls (normotensive), SBP $<120 \mathrm{mmHg}$ and $\mathrm{DBP}<80 \mathrm{mmHg}$; Cases (hypertensive), SBP $\geq 140 \mathrm{mmHg}$ and/or DBP $\geq 90$ $\mathrm{mmHg}$ and/or antihypertensive medication. ${ }^{* *}$ Significant differences in characteristics between the normotensive and hypertensive subjects were determined by the two-tailed Student's t-test. 
Table 2. The significant association results of SNPS in the MACROD2 gene with blood pressures and hypertension in the KARE

\begin{tabular}{|c|c|c|c|c|c|c|c|c|c|c|c|}
\hline \multirow{2}{*}{ No. } & \multirow{2}{*}{ SNP } & \multirow{2}{*}{$\begin{array}{l}\text { Minor } \\
\text { allele }\end{array}$} & \multicolumn{2}{|c|}{ MAF } & \multirow{2}{*}{ Function } & \multicolumn{2}{|c|}{$\begin{array}{l}\text { Hypertension } \\
\text { (controls 4450: cases } 1968 \text { ) }\end{array}$} & \multicolumn{2}{|l|}{ SBP } & \multicolumn{2}{|l|}{ DBP } \\
\hline & & & Cases & Controls & & OR $(95 \% \mathrm{Cl})$ & Add $P$ & Beta \pm se & Add $P$ & Beta \pm se & Add $P$ \\
\hline 1 & rs6110206 & $\mathrm{T}$ & 0.367 & 0.382 & intron & $0.90(0.83 \sim 0.98)$ & $\underline{0.019}$ & $-0.26 \pm 0.27$ & 0.325 & $-0.17 \pm 0.18$ & .342 \\
\hline 2 & rs6042613 & $\mathrm{T}$ & 0.367 & & intron & $0.91(0.83 \sim$ & $\underline{0.024}$ & $27 \pm 0.27$ & & \pm 0.18 & 401 \\
\hline 3 & rs17263597 & C & 0.392 & 0.414 & intron & $0.91(0.84 \sim 0.99)$ & 0.031 & $-0.39 \pm 0.26$ & 0.133 & $1 \pm 0.18$ & 0.232 \\
\hline 4 & rs1998238 & C & 0.396 & 0.419 & intron & $0.91(0.84 \sim 0.99)$ & $\underline{0.034}$ & $-0.43 \pm 0.26$ & 0.103 & $-0.25 \pm 0.18$ & 0.164 \\
\hline 5 & rs2208453 & $\mathrm{T}$ & 0.394 & 0.413 & intron & $0.91(0.84 \sim 0.99)$ & $\underline{0.031}$ & $-0.39 \pm 0.26$ & +1 & $-0.20 \pm 0.18$ & 0.261 \\
\hline 6 & rs994567 & $\mathrm{T}$ & 0.393 & 0.413 & intron & $0.92(0.84 \sim$ & $\underline{0.038}$ & $-0.36 \pm 0.26$ & 0.166 & $-0.19 \pm 0.18$ & 0.282 \\
\hline 7 & rs6110305 & C & 0.232 & 0.248 & intron & $0.90(0.82 \sim 0.99)$ & 0.028 & $-0.43 \pm 0.30$ & 0.1 & $-0.01 \pm 0.21$ & 0.951 \\
\hline 8 & rs16996211 & $\mathrm{T}$ & 0.161 & 0.187 & intron & $0.85(0.76 \sim 0.95)$ & $3.1 \times 10^{-3}$ & $-0.75 \pm 0.33$ & $\underline{0.024}$ & $-0.59 \pm 0.23$ & 0.010 \\
\hline 9 & rs6034240 & C & 0.122 & 0.135 & intron & $0.83(0.74 \sim 0.94)$ & $4.2 \times 10^{-3}$ & $-0.62 \pm 0.38$ & 0.098 & $-0.61 \pm 0.26$ & $\underline{0.018}$ \\
\hline 10 & rs17705904 & $\mathrm{C}$ & 0.030 & 0.025 & intron & $1.30(1.01 \sim 1.67)$ & $\underline{0.038}$ & $1.21 \pm 0.80$ & & $0.75 \pm 0.55$ & 0.167 \\
\hline 11 & rs6080048 & $\mathrm{T}$ & 0.260 & 0.247 & intron & $1.10(1.00 \sim 1.21)$ & 0.047 & $0.48 \pm 0.30$ & 0.1 & $0.31 \pm 0.20$ & 0.128 \\
\hline 12 & rs6110847 & $\mathrm{T}$ & 0.256 & 0.243 & intron & $1.10(1.01 \sim 1.21)$ & 0.038 & $0.50 \pm 0.30$ & 0.098 & $0.32 \pm 0.20$ & 0.119 \\
\hline 13 & rs6080057 & G & 0.250 & 0.238 & intron & $1.11(1.01 \sim 1.22)$ & $\underline{0.036}$ & $0.47 \pm 0.30$ & 0.116 & $0.28 \pm 0.20$ & 0.171 \\
\hline 14 & rs6080069 & A & 0.252 & 0.239 & intron & $1.12(1.02 \sim 1.23)$ & $\underline{0.022}$ & $0.50 \pm 0.30$ & 0.096 & $0.28 \pm 0.20$ & 0.168 \\
\hline 15 & rs6074984 & C & 0.255 & 0.243 & intron & $1.12(1.02 \sim 1.23)$ & 0.024 & $0.51 \pm 0.30$ & 0.087 & $0.29 \pm 0.20$ & 0.158 \\
\hline 16 & rs775109 & $\mathrm{T}$ & 0.193 & 0.172 & intron & $1.13(1.02 \sim 1.26)$ & $\underline{0.020}$ & $0.47 \pm 0.34$ & 0.162 & $0.33 \pm 0.23$ & 0.148 \\
\hline
\end{tabular}

Abbreviations: beta, regression coefficient; $\mathrm{Cl}$, confidence interval; KARE, Korean association resource; MAF, minor allele frequency; OR, odds ratio; se, standard error; SNP, single nucleotide polymorphism; Controls (normotensive), SBP $<120 \mathrm{mmHg}$ and DBP $<80 \mathrm{mmHg}$; Cases (hypertensive), SBP $\geq 140 \mathrm{mmHg}$ and/or DBP $\geq 90 \mathrm{mmHg}$ and/or antihypertensive medication. Statistically significant values $(P<0.05)$ are indicated in bold and underline.

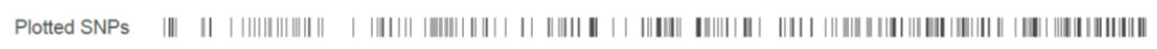

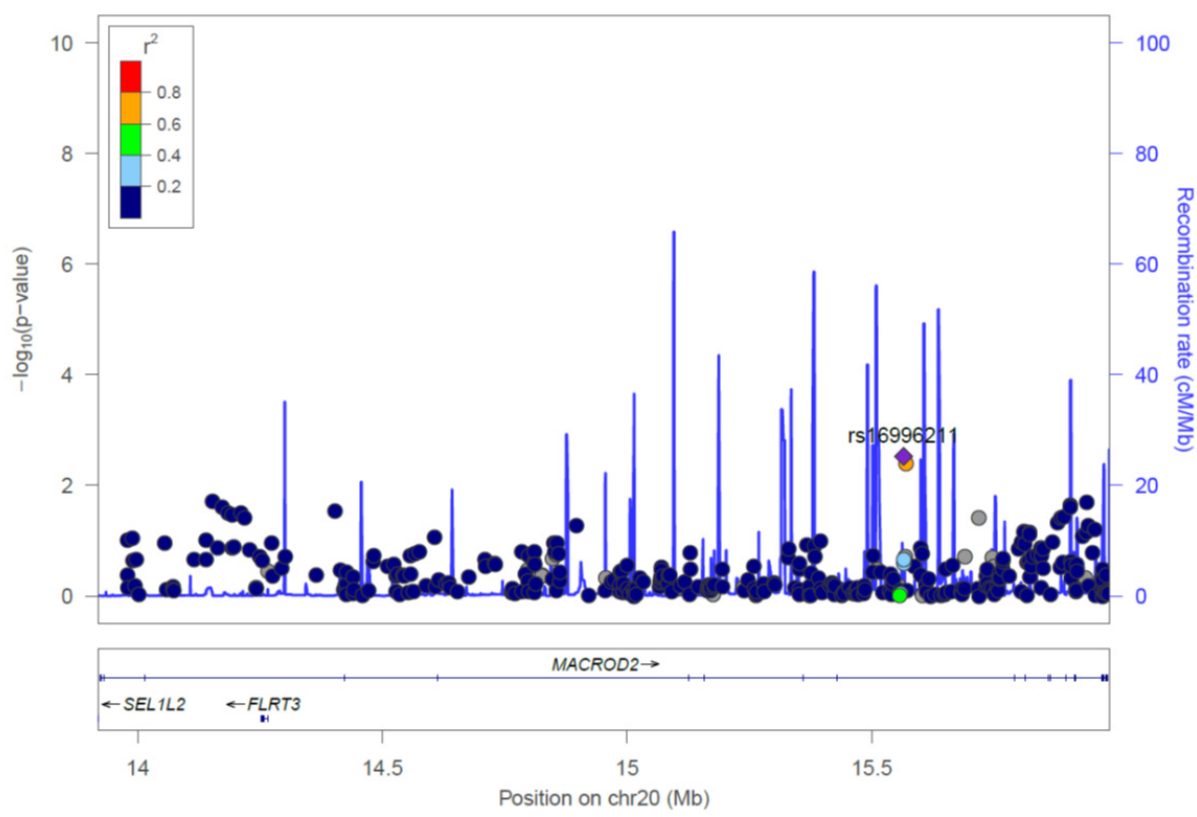

Figure 1. Associations between MACROD2 SNPS and hypertension in Korean population. The positions of the SNPS are shown at the top of the figure, and associations between SNPs in the MACROD2 gene and hypertension in Korean subjects are shown in the middle. The statistical significances (- $\log _{10} P$ value) of associations with the SNPs are plotted. The recombination rates estimated using HapMap Asian population data is shown by a blue line. The purple diamond with a SNP number represents the SNP most strongly associated with hypertension, and its correlations with other SNPs are shown by colors indicating the levels of linkage disequilibrium $\left(R^{2}\right)$. At the bottom of the figure, the nucleotide position of the MACROD2 gene on chromosome 20 (NCBI build 36) is shown.

\section{MACROD2 유전자의 유의한 SNP들에 대한 in silico 기능 분석}

고혈압에서 통계적인 유의성을 보이는 $M A C R O D 2$ 의 $\mathrm{SNP}$ 들 이 어떻게 유전자 혹은 단백질에 영향을 미칠 것인지를 Regulome DB (http://www.reguloumdb.org/index)와 HaploReg (http://archive.broadinstitute.org/mammals/haploreg/ haploreg_v3.php)에서 in silico 기능 분석을 해 보았다. 확인 결과 고혈압 상태와 혈압 수치에서 공통적으로 유의하게 나타 난 두 개의 SNP (rs16996211, rs6034240) 중에서 rs16996211은 Regulome DB와 HaploReg에서 모두 motif 변 화를 예측하고 있다. 따라서, rs16996211의 유전형에 따라 
Table 3. Results of the Regulome DB and HaploReg of two SNP in the MACROD2 gene

\begin{tabular}{|c|c|c|c|c|c|c|c|c|c|c|}
\hline \multirow[b]{2}{*}{ SNP } & \multirow[b]{2}{*}{ A1 } & \multirow[b]{2}{*}{ A2 } & \multicolumn{5}{|c|}{ Regulome DB } & \multicolumn{3}{|c|}{ HaploReg } \\
\hline & & & Score & TFBS & DNase & $\begin{array}{l}\text { Proteins } \\
\text { bound }\end{array}$ & Motifs & DNase & $\begin{array}{c}\text { Enhancer histone } \\
\text { marks }\end{array}$ & $\begin{array}{l}\text { Motifs } \\
\text { changed }\end{array}$ \\
\hline rs16996211 & $\mathrm{T}$ & $A$ & 6 & & & & Freac-7, HFH8(FOXF1A), Foxa2 & & 4 organs & 9 altered motifs \\
\hline rs6034240 & $C$ & $\mathrm{~T}$ & 4 & + & + & CTCF & & & BRST, BRN & Hoxb9, Pou5f1 \\
\hline
\end{tabular}

Abbreviations: SNP, single nucleotide polymorphism; A1, minor allele; A2, major allele; TFBS, transcription binding factor site; +, affect; RegulomeDB is a database that annotates SNPs with known and predicted regulatory elements in the intergenic regions of the $\mathrm{H}$. sapiens genome (http://www.regulomedb.org/index); HaploReg is a tool for exploring annotations of candidate regulatory SNPs (http://archive.broadinstitute.org/mammals/haploreg/haploreg_v3.php).

$M A C R O D 2$ 유전자 발현에 영향을 미칠 가능성을 보여주고 있 었다. 또한 rs6034240은 DNase peak 차이가 있다는 것을 확인 할 수 있었고 HaploReg에서는 전사 인자인 Hoxb9와 Pou5f1 의 결합 motif로 작용하기 때문에 이 역시 $M A C R O D 2$ 유전자 발현에 영향을 줄 가능성을 보여주고 있다(Table 3).

\section{고 찰}

본 연구에서는 한국인을 대상으로 $M A C R O D 2$ 유전적 다형 성(341개 SNP)과 혈압 수치 및 고혈압 상태에 대한 상관 분석을 시행하였다. 고혈압 환자의 경우 수축기 혈압의 평균과 이완기 혈압의 평균 수치들이 각각 고혈압의 기준인 $140 \mathrm{mmHg}, 90$ $\mathrm{mmHg}$ 보다 낮은 수치를 보여주고 있는데, 이것은 고혈압 환자 군에 고혈압 약을 복용하여 원래 자신의 혈압보다 낮은 혈압으 로 측정된 사람들이 포함되었기 때문이다.

$M A C R O D 2$ 유전자에서 $\mathrm{SNP}$ 의 고혈압 환자군과 건강 대조 군 간의 $\mathrm{MAF}$ 차이에 따른 통계적 유의성을 분석하여 유전적 변 이에 따른 고혈압 상태와의 상관성에 대하여 알아보고자 하였 다. 그 결과 16 개의 SNP에서 고혈압 상태와 통계적으로 의미 있 는 유의성이 확인되었다. 이들 고혈압 상태와 관련 있는 $\mathrm{SNP}$ 들 중에서 혈압에서도 동일한 방향성의 유의한 관계를 보이는 $\mathrm{SNP}$ 는 2개였다. 이러한 결과는 $M A C R O D 2$ 유전자의 다형성이 혈압수치 및 고혈압상태와의 상관관계를 뒷받침해준다(Table 2).

본 연구에서는 대규모 유전체 역학 코호트를 이용한 연구로, $M A C R O D 2$ 의 특정 $\mathrm{SNP}$ 들이 혈압에 영향을 미칠 것이라는 가 능성을 제시해 주고 있다. 하지만 $M A C R O D 2$ 가 어떻게 고혈압 에 영향을 미치는지에 대해서는 직접 실험을 진행하지 않아 in Silico를 통해서 간접적으로 알 수 있다는 한계점이 있다.

그러나 앞서 고혈압과 $\mathrm{MACROD} 2$ 와의 관계를 분석한 연구 에서[11], Vascular adhesion protein-1 (VAP-1)이 성숙한 지 방 세포에서 고도로 발현되어 순환계로 방출되는 막 결합 아민 산화 효소로 이는 당뇨병, 고혈압 등 여러 병리학적 과정에 매우
연관되어 있으며 $M A C R O D 2$ 가 지방 생성 유전자 발현과 인간 지방 세포에서의 VAP- 1 의 발현을 조절한다는 것을 밝혔다. 또 한 MACROD2의 exon 결실이 비만과 연관이 있다는 연구[15] 를 통해 MACROD2가 비만과 밀접한 관계가 있다는 것을 알 수 있으며 비만은 고혈압과의 직접적인 관련이 있는 만큼 이와 관 련하여 분석한다면 더욱 확실한 연구가 될 것이다.

$M A C R O D 2$ 와 고혈압에 관해 분석한 Slavin 등[10]의 논문 에서는 Wellcome Trust Case Control Consortium (WTCCC) 이라는 United Kingdom (UK)의 데이터를 이용하여 coronary artery disease (CAD)와 hypertension (HTN)에 대해 Two-marker logistic model association test를 실시하였고, $\mathrm{HTN}$ 의 분석결과 GPR69, XRCC4, MYO6, ZFAT, MACROD2 에서 유의성이 확인되었으며 그 중 ZFAT와 $M A C R O D 2$ 는 고혈 압과의 상관성이 입증되었다[13, 18, 19].

본 연구에서는 KARE 데이터를 이용하여 고혈압에 대해 로지 스틱 회귀분석을 실시하였고, 앞선 연구에서는 다중 마커를 이 용하여 고혈압과 관상동맥질환에 대해 분석하여 각각의 질병과 연관된 유전자를 밝혔다. 본 연구에서는 단일 마커를 이용하여 분석하였으며 앞선 연구에서 유의하게 나타났던 $M A C R O D 2$ 의 rs200752와 rs200759 사이의 SNP는 UCSC Genome Browser on Human Mar. 2006 (NCBI human genome build 36) 기준으로 했을 때 본 연구의 분석 대상 SNP에는 존재하지 않아 확인할 수 없었다. 또한 앞선 연구에서 다중 마커로 사용했 던 rs200752와 rs200759는 고혈압과의 상관성을 나타내지 않 았다. 앞선 연구에서도 마커로 사용된 rs200752와 rs200759 가 고혈압과 관련이 있다고 밝힌 것이 아니고 rs200752와 rs200759 사이의 SNP가 고혈압과 상관성이 있다고 밝혔으므 로, 이는 인종과는 상관이 없다는 것을 알 수 있다. 그러나 본 연 구에서 혈압과 관련된 $M A C R O D 2$ 의 다른 SNP들을 찾을 수 있 었으며 이를 바탕으로 고혈압과 $M A C R O D 2$ 의 연관성을 밝힐 수 있었다.

ZFAT는 T세포 항상성과 $\mathrm{T}$ 세포 수용체 매개반응 등 면역과 
관련되어 있다고 알려진 유전자로, 분석 결과 60 개의 $\mathrm{SNP}$ 중수 축기 혈압과 이완기 혈압에서는 연관성이 나타나지 않았고, 고 혈압에 대해서는 22개의 SNP에서 유의성이 확인되었으나, 본 연구에서는 수축기 혈압과 이완기 혈압에 영향을 받는 고혈압 에 대한 연구를 목적으로 한 연구이기 때문에 ZFAT는 이번 연구 에서 고려하지 않았다.

$M A C O R D 2$ 는 전사체의 길이가 약 $2 \mathrm{Mb}$ 인 긴 유전자이기 때 문에 다른 많은 질병과 역할에 연관되어 있다. 예를 들어 양성 유 방암의 세포는 핵에 단백질 수용체를 만들고 에스트로겐과 결 합하여 성장하며 이를 치료하는데 타목시펜이 사용된다. 타목 시펜은 단백질 수용체와 결합하여 에스트로겐의 결합을 방해하 여 암 세포의 성장을 억제하지만 일부 에스트로겐 양성 유방암 은 이러한 타목시펜에 내성이 생기게 되어 이에 대한 치료 효과 가 감소한다. 또한 타목시펜 내성 유방암 세포는 $M A C R O D 2$ 를 과발현 시키고 이종 이식 시험에서 에스트로겐의 독립적인 성 장을 유도하기 때문에 $M A C R O D 2$ 의 발현 및 증폭의 증가를 에 스트로겐의 독립적인 성장과 타목시펜 내성의 마커로 활용될 수 있다[20].

또한 $M A C R O D 2$ 결실이 대장암의 발병에 영향을 준다는 것 이 밝혀졌다. 염색체 불안정성은 암의 주요 특징으로, $M A C R O D 2$ 의 haplo insufficiency는 이를 증가시켜 Poly ADP-ribose] polymerase 1 (PARP1) 활성의 억제를 일으켜 DNA 복구를 손 상시켜 장의 종양 성장을 촉진한다[21].

그동안 많은 연구에서 고혈압의 상태와 관련하여 환경적 요 인과 유전적 요인에 대한 연구들이 진행되어 왔다[5, 22-25]. 본 연구는 고혈압에 대해 한국인의 유전체 역학 자료를 기반으 로 분석했을 때에도 MACROD2의 유전적 변이들이 혈압 및 고 혈압 상태와의 상관관계가 성립되는지를 확인하였으며, 이러 한 결과를 통해 $M A C R O D 2$ 유전자는 인종이나 인구집단에 상 관없이 공통적으로 혈압에 영향을 미치는 유전자임을 유추할 수 있었다.

\section{요 약}

고혈압은 유전적, 환경적 요인들이 복합적으로 작용하여 발 생하는 질환으로, 선진국들의 경우에는 성인들의 $30 \%$ 이상이 고혈압 상태인 매우 유병률이 높은 만성 질환이다. 고혈압에 영 향을 미치는 유전적 요인들 중에서 $M A C R O D 2$ 유전자의 변이 들이 백인 중심의 코호트 연구에서 혈압 및 고혈압 상태와 상관 관계가 있다는 보고들이 있다. 이에 본 연구에서는 질병관리본 부에서 생산 구축한 한국인 유전체 역학 자료를 바탕으로
$M A C R O D 2$ 유전자 영역의 유전 변이들을 선택 추출한 후에 고 혈압 상태에 대한 로지스틱 회귀분석을 시행하였고, 수축기 혈 압과 이완기 혈압에 대해서는 선형 회기 분석을 진행하였다. 그 결과 고혈압 상태에서 16 개 SNP들이 유의한 상관관계를 보여 주었고, 이들 중 2개의 SNP (rs16996211, rs6034240)은 혈압 에서도 통계적 유의성을 보여주고 있다. 가장 유의성이 높은 rs16996211은 고혈압의 상대적 위험도가 0.85 (CI: 0.76 $0.95, P=3.1 \times 10^{-3}$ )이고, 수축기 혈압은 (beta=-0.75, $P=0.024)$ 의 이완기 혈압은(beta=-0.59, $P=0.01$ )의 상관 분석 결과를 보여주었다. 이러한 결과들을 통해 $M A C R O D 2$ 유전자 의 다형성은 백인 중심의 서양인 뿐만 아니라 한국인에서도 고 혈압과 상관관계가 있는 것을 확인할 있었으며, 이러한 사실은 고혈압의 병리 기전에 대한 유전적 상호관계의 이해를 높일 것 으로 기대한다.

Acknowledgements: This study was supported by Basic Science Research Program through the National Research Foundation of Korea (NRF) funded by the Ministry of Education (NRF-2017R1D1A3B03034752). This study was conducted with bioresources from National Biobank of Korea, the Centers for Disease Control and Prevention, Republic of Korea (2017-046).

Conflict of interest: None

Author's information (Position): Ko B, Undergraduate student; Jin HS, Professor.

\section{REFERENCES}

1. Carretero OA, Oparil S. Essential hypertension. Part I: definition and etiology. Circulation. 2000;101:329-335.

2. Fields LE, Burt VL, Cutler JA, Hughes J, Roccella EJ, Sorlie P. The burden of adult hypertension in the United States 1999 to 2000: a rising tide. Hypertension. 2004;44:398-404. https://doi.org/10.1161/01.HYP.0000142248.54761.56.

3. Lawes CM, Vander Hoorn S, Rodgers A, International society of hypertension. Global burden of blood-pressure-related disease, 2001. Lancet. 2008;371:1513-1518. https://doi.org/ 10.1161/HYPERTENSIONAHA.113.01148.

4. Yannoutsos A, Dreyfuss Tubiana C, Safar ME, Blacher J. Optimal blood pressure target in stroke prevention. Curr Opin Neurol. 2017;30:8-14. https://doi.org/10.1097/WCO.0000000000000407.

5. Jin HS, Hong KW. Replication of an African-American GWAS on blood pressure and hypertension in the Korean population. Genes \& Genomics. 2011:33-127. https://doi.org/10.1007/ s13258-010-0138-y.

6. Ministry of Health and Welfare, Korea Health Industry 
Development Institute. Ministry of Health and Welfare, Korea Centers for Disease Control and Prevention. The 7th Korea National Health and Nutrition Examination Survey (KNHANES VII-1) [Internet]. Asan: Korea Centers for Disease Control and Prevention; 2018 [cited 2018 October 09]. Available from: https://knhanes.cdc.go.kr/knhanes/index.do.

7. Yang L, Tian RG, Chang PY, Yan MR, Su XL. Association of SNPs in the PPARgamma gene and hypertension in a Mongolian population. Genet Mol Res. 2015;14:19295-19308. https://doi.org/10.4238/2015.December.29.39.

8. Li W, Liu C. The $-344 \mathrm{C} / \mathrm{T}$ polymorphism in the CYP11B2 gene is associated with essential hypertension in the Chinese. JRAAS. 2014;15:150-155. https://doi.org/10.1177/1470320312466928.

9. Qin L, Zhao P, Liu Z, Chang P. Associations SELE gene haplotype variant and hypertension in Mongolian and Han populations. Intern Med. 2015;54:287-293. https://doi.org/ 10.2169/internalmedicine.54.2797.

10. Slavin TP, Feng T, Schnell A, Zhu X, Elston RC. Two-marker association tests yield new disease associations for coronary artery disease and hypertension. Hum Genet. 2011;130:725-733. https://doi.org/10.1007/s00439-011-1009-6.

11. Chang YC, Hee SW, Lee WJ, Li HY, Chang TJ, Lin MW, et al. Genome-wide scan for circulating vascular adhesion protein-1 levels: MACROD2 as a potential transcriptional regulator of adipogenesis. J Diabetes Investig. 2018. https://doi.org/10. 1111/jdi.12805.

12. Kelly TN, Takeuchi F, Tabara Y, Edwards TL, Kim YJ, Chen P, et al. Genome-wide association study meta-analysis reveals transethnic replication of mean arterial and pulse pressure loci. Hypertension. 2013;62:853-859. https://doi.org/10.1161/ HYPERTENSIONAHA.113.01148.

13. Zhu X, Feng T, Li Y, Lu Q, Elston RC. Detecting rare variants for complex traits using family and unrelated data. Genet Epidemiol. 2010;34:171-187. https://doi.org/10.1002/gepi.20449.

14. Maas NM, Van de Putte T, Melotte C, Francis A, Schrander-Stumpel CT, Sanlaville D, et al. The C20orf133 gene is disrupted in a patient with Kabuki syndrome. J Med Genet. 2007;44:562-569. http://dx.doi.org/10.1136/jmg.2007.049510.

15. Pettersson M, Viljakainen H, Loid P, Mustila T, Pekkinen M, Armenio M, et al. Copy number variants are enriched in individuals with early-onset obesity and highlight novel pathogenic pathways. J Clin Endocrinol Metab. 2017;102:3029-3039. https://doi.org/10.1210/jc.2017-00565.
16. Cho YS, Go MJ, Kim YJ, Heo JY, Oh JH, Ban HJ, et al. A large-scale genome-wide association study of Asian populations uncovers genetic factors influencing eight quantitative traits. Nat Genet. 2009;41:527-534. https://doi.org/10.1038/ ng.357.

17. Pruim RJ, Welch RP, Sanna S, Teslovich TM, Chines PS, Gliedt $\mathrm{TP}$, et al. Locus zoom: regional visualization of genome-wide association scan results. Bioinformatics. 2010;26:2336-2337. https://doi.org/10.1093/bioinformatics/btq419.

18. Ciullo M, Bellenguez C, Colonna V, Nutile T, Calabria A, Pacente R, et al. New susceptibility locus for hypertension on chromosome 8q by efficient pedigree-breaking in an Italian isolate. Hum Mol Genet. 2006;15:1735-1743. https://doi.org/10.1093/hmg/ddl097.

19. Cotsapas C, Speliotes EK, Hatoum IJ, Greenawalt DM, Dobrin R, Lum PY, et al. Common body mass index-associated variants confer risk of extreme obesity. Hum Mol Genet. 2009;18:3502-3507. https://doi.org/10.1093/hmg/ddp292.

20. Mohseni M, Cidado J, Croessmann S, Cravero K, CiminoMathews A, Wong HY, et al. MACROD2 over expression mediates estrogen independent growth and tamoxifen resistance in breast cancers. Proc Natl Acad Sci U S A. 2014;111: 17606-17611. https://doi.org/10.1073/pnas.1408650111.

21. Sakthianandeswaren A, Parsons MJ, Mouradov D, MacKinnon RN, Catimel B, Liu S, et al. MACROD2 haploinsufficiency impairs catalytic activity of PARP1 and promotes chromosome instability and growth of intestinal tumors. Cancer Discov. 2018;8:988-1005. https://doi.org/10.1158/2159-8290.CD-17-0909.

22. Jin HS, Sober S, Hong KW, Org E, Kim BY, Laan M, et al. Age-dependent association of the polymorphisms in the mitochondria-shaping gene, OPA1, with blood pressure and hypertension in Korean population. Am J Hypertens. 2011; 24:1127-1135. https://doi.org/10.1038/ajh.2011.131.

23. Jin HS. Gender-specific association of the ANO1 genetic variations with hypertension. Biomed Sci Lett. 2015:144-151. https://doi.org/10.15616/BSL.2015.21.3.144.

24. Hong KW, Jin HS, Lim JE, Cho YS, Go MJ, Jung J, et al. Non-synonymous single-nucleotide polymorphisms associated with blood pressure and hypertension. J Hum Hypertens. 2010;24:763-774. https://doi.org/10.1038/jhh.2010.9.

25. Kim HK, Leem KH, Lee SN, Hong MS, Jung KH, Kim SK, et al. CACNA1A gene polymorphism is associated with hypertension in Korean population. Biomed Sci Lett. 2009;15:31-35. 